\title{
The Research on the Development Trends of Ink Element in the Packaging Design \\ Songqi Yao ${ }^{1, a}$, Xiao Chen ${ }^{2, b}$ \\ ${ }^{12}$ Pingxiang University, Pingxiang, Jiangxi, China, 337000 \\ aemail, ${ }^{b}$ email
}

Keywords: Ink Element, Packaging Design, Research

\begin{abstract}
Chinese Painting Art history is one of the most unique human being is unique Chinese civilization, but also a treasure of traditional Chinese culture. With the development of modern art, the mutual penetration and influence cross fusion between different kinds of art has become an inevitable trend of history, in the East-West cultural collision continues today, to use ink art packaging design more and more common, which is China a traditional cultural inheritance. This paper describes the traditional ink painting art visual arts element contained in Packaging Design to further discuss ways and integration of both trends.
\end{abstract}

\section{Introduction}

We live in a design is everywhere in society, all aspects are permeated with great charm design. In the East-West cultural collision continues today, we have to seek the integration point between ink painting and packaging design, so that they have access to innovations in performance. Ink has its own unique artistic features of thinking, can provide a steady stream of nutrients for our packaging design to promote their ideas and impact in the form of, alternately, integration, the two sides will bring a different kind of style, you can enhance packaging design grade, played a role in fueling. We should deeply understand the ink of the essence, fully aware of packaging design form language, mastery, to be effective in combination, so as to promote ink elements play a vital role in packaging design, in order to enable us to find really belong to the local, but also the world identity packaging design.

\section{The Characteristics of Ink Art}

The Natural Features. In the early paintings, the atmosphere is very universal respect for nature, different historical era for the "natural" are not the same understanding. Ink painting from nature, but also reflects the changes in the rhythm of the nature of life. More and more artists of the literature on the nature of the ink used in the pursuit of art, often in the creation of nature as ideal, so that the ink has a "natural" artistic features. Ink art emphasizes of sincere thoughts and feelings natural to express, to reflect the true nature of emotions, to make the screen image of nature, manifestations without embellishment, not false exterior, primitive nature, not deliberate, but rather the natural heart to show things in the world. "Intentionally caused unintentional, inadvertent and intentional of" This is the artist the highest realm of art, only to observe nature in life, to borrowing from nature. Ink Art is so work out naturally, but also in line with nature. In the process of writing ink must emphasize natural. This special ink material, unlike painting, gouache material, layer by layer superimposed Videos badly can be repeated again, and the ink is different, on paper and silk performance, requiring the skill and then cannot draw altered, the pursuit of the true nature of the show.

The Simple Features. The second feature of ink painting is "simple", that "less is more", "pit one against ten," ink painting simple pictures, often with very few elements to convey the most information. "Virtual and real, not painted at all into Wonderland," Chinese painting is a summary of the culture minimalist aesthetic. [1] Ink Art "simple" feature not a general sense of simple, sloppy, sloppy, but to the delight of dripping and emptying in several pens, meaning cross wide, rely on non-OF profound literacy, the skill cannot, its image is simple, rich in meaning, very few elements 
to convey more information. Few pens show features old drunken intoxicated state, reflecting the painter bold and uninhibited personality. In Chinese ink art works we can often see a lot of blank space processing, which is the simple handling, though not inked, but it can appeals to the imagination. Ink art with particular emphasis teaser where, to cut unnecessary details, so that the screen virtual and real, prioritize. This "simple" art should reflect the characteristics of the good must also rely on tips to help support, ask authors have a considerable degree of ink accomplishment, has strong generalization ability and proficient skills, otherwise rely on "simple" unlimited features to express emotion and it is impossible.

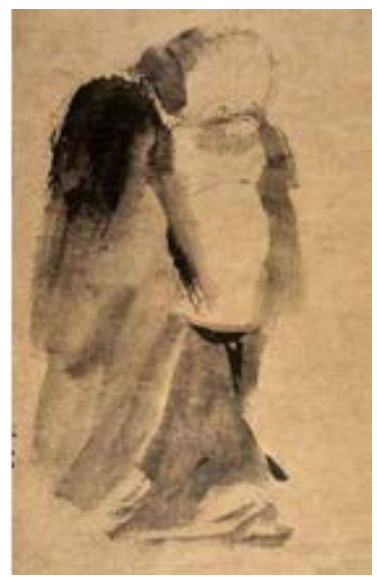

Fig.1

The Ethereal Features. Ethereal is the most mysterious Chinese ink art artistic features, it embodies the soul of art. The so-called ethereal, dreamy hazy is through artistic symbols to reflect the spirit and emotion of the gods change, is the creator of assiduous artistic effect, it is one of the important evaluation criterion works of art. Ethereal itself is "turning a blind eye and a deaf ear," something that is kind of hard to grasp the spiritual realm we can say "no intention" of the intention is the "inaction" of the committed. Vacant by the actual situation manifested processing screen, virtual invisible, indeed tangible. Qi Baishi elderly good at painting shrimp (Fig. 2), shrimp in many works, we can feel ethereal features Chinese ink painting. Baishi on white paper usually have traces of water, but let the water through the feeling we read performance of the screen, focusing on the performance of the shrimp, shrimp has been highlighted, the water is virtual students, Baishi full use of ink to reflect the actual situation ethereal features vivid, high attainments. Ink art symbol "ethereal" characterized by returning to the vanity of the mind, emotion, there are concrete things in reality, the real from the air and, in fact, you are available, there is a real air, ethereal tautomers, which formed ink Art "ethereal" feature. [2]

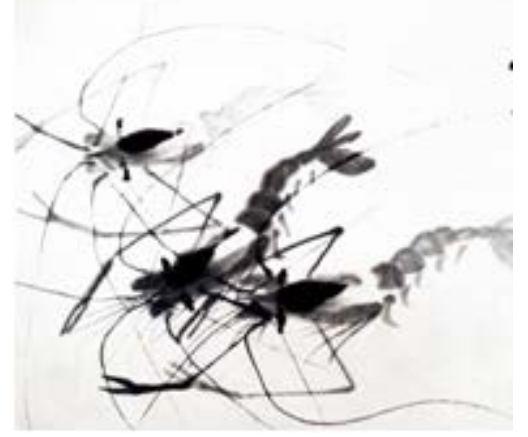

Fig.2

The Features of Black and White. Ink art, there is a notable feature is the black and white as the main color painting. Ink works at is a real representative, and the white part of the artistic process contains more virtual mood. In the works of black have a stable effect, there is a sense of weight, which gives a large area of white light, crisp, elegant feeling. Under the black and white contrast, black is very stable, and white is very jump, so White must fully to grasp its size, more stable gray screen damage, effects and distracting; less obvious contrast makes the picture look pale. 
"No spirit, "eclipsed. Black and white is a unique feature of Chinese ink art, but also distinguish the most direct language other painting system has a unique artistic charm of Chinese painting is the most basic and essential thing, and also the essence of Chinese ink.

\section{The Analysis of Ink Art Intervention in Packaging Design}

Chinese Painting a thousand years of history, the Chinese nation created a unique aesthetic qualities and perception capabilities, and gradually become the representative of Chinese traditional art. Ink applied to the art of packaging design can play a role in conveying the spirit of the connotation of modern graphic design and future, are bound to have a huge impact is undeniable, ink art of packaging design provides a wealth of nutrients and long-term development.

Ink is unique materials and technology skills used, to give us a new heart and comprehend language, when it come together with the package design, as water and ink Blending and Infiltrating the same wonderful changes will happen on rice paper, will make each other spectacular. Ink is a living, ink is spiritual, if it can have on your creativity and spirituality that integrate life, seek fusion point ink art and packaging design, and seek the best combination of their inner feelings and designers this will be a great step forward. Fully tap the local art and development with special emphasis on Chinese ink art element in the use of packaging design and it has a very important significance. Absorbing the essence of ink art, reasonable, clever applications, not only brought a new approach to packaging design ideas, explore the idea of increasing the implication, but also inherit and carry forward ink art has opened up a new path. The exchange of Chinese and Western art and culture, the two sides will bring new artistic language, this fusion complementary, creating a world-class visual language without boundaries, communication Chinese and Western cultures.

Use ink art and packaging design combined, it can produce a strong visual impact, to highlight the tradition and history, designed to deepen cultural connotation and tasting flavor. The more national character the more international, our designers should absorb the essence of Western design, to dig deeper Chinese ink painting to make between modern and traditional fusion penetration, heritage, beyond the closing of the flow path. Ink seepage only through contact brush with rice paper, can produce dramatic changes in its shape and color, computer technology is difficult to do. Special use ink, packaging design has become an important issue, with a deep knowledge of ink and accomplishment for intelligent design played a significant role to play, the combination of the two has a broad future.

\section{The Reproduced Development of Ink Element in Packaging Design}

With the advent of the digital age, social progress, product packaging more and more people's attention, people packaging design style have higher requirements. Packaging design should not only have good technology designed to protect the transport of goods but also conducive to the circulation, while also both good visual effects designed to ensure the smooth sale of goods. With the ink art packaging design its own development and progress, both there was a certain combination of points, in the packaging design clever use of traditional ink art as a commodity packaging design elements, combined with modern science and technology, into the modern design of the forms make use of ink art gets a new value and elevates the packaging has a strong sense of the times and national sense, filling brand personality characteristics of commodity circulation, it has a positive role in promoting sales.

Modern packaging design directly reflects people's lives and aesthetic appeal and it is the material life and spiritual aesthetic carrier, today, various commodities packaging designs tend to be more local characteristics. Traditional ink art for the majority of designers to provide a broad stage, a lot of good packaging design work over many years is still remembered by the people, the main reason is that the designers captured the emotional needs of consumers deep inside. Some excellent designers had put into the design mix calligraphy, has formed a Japanese packaging design style, this design is a prominent theme, deliver accurate information and strong visual impact, can cause the attention of consumers, so as to arouse people's purchasing desire most to achieve marketing 
purposes. Ink as a design element in the packaging design of the more common, but often seen in those with Chinese local characteristics of the product packaging, in the historic. Such as: tea, wine, dates, pen, ink, local handicrafts they will use more ink abstract elements to break up, after further graphic appears in the package. Making techniques and modern design combined with traditional.

Tea is the most natural fit thing and it has a long history and profound traditional heritage. In modern tea packaging design view, with ink as the main performance of the majority, with a running script, cursive writing the main text, matched with pure tea consistent graphics and patterns, both played well in the decoration effect, and also very coordinated with the nature of the goods. Ink art tea packaging design allows the use of more traditional flavor, reflecting the noble, elegant, simple, stylish design. Artistically perfect combination of tea culture is able to highlight the traditional Chinese culture and language, so use ink graphics, calligraphy font as tea packaging visual elements are just right, it can accurately express their flavor, make tea fragrance and elegance and Chinese ink. Chinese ink painting has a broad mass base, better access to consumers, so more sales can play a catalytic role. Ink is splendid Chinese cultural treasures, it transcendental artistic conception detached refined mood state and tea culture is seeking to convey to coincide.

Wine is one of the material civilization of the Chinese nation and the product logo and packaging wine in the history of thousands of years, are two mutually interactive industry integration, mutual promotion and development go hand in hand, glorified, wine products, packaging after becoming commodities into circulation. Today, wine and external packaging design emphasizes the unique style design, sales of wine plays an important role in publicity and promotion. Consumers wine packaging design also put forward higher requirements. "Fen" package design uses Chinese calligraphy, Chinese characters in the packaging design as a graphic image appears. Running script to reflect with a thick, running graphical processing into very joy of life, combined with the effect of the actual situation, with changeable ink simply and clearly highlight the theme, concise and clear, quiet and dignified, reveals a deep sense of Chinese flavor. [3] The famous brand of Hubei Province, "China Jin wine" package design, ink use changes, blurring the reality process, change the book body, all exhibit oriental arts pay attention to the "mood", "charm . " From the works, the designer cursive calligraphy by "powerful" vigorous, uninhibited, vigorous Emotion reflects the wine properties of wine. Calligraphic find the perfect product for a combination of points, if the "powerful" words cannot express the meaning of this vigorous, uninhibited by Seal or regular script, but easy to mislead the consumer product concept to understand. Visible, characters in packaging design is a problem cannot be ignored, for different styles of calligraphy products also need to be carefully considered, while the text must be clear, prominent, eye-catching. It can occur simultaneously with the pattern of the packaging design illustrations; also can occur alone, the package to form a unique style. Cursive "powerful" words flying out vigorous and effective Cursive name, Crafts wear fork cross-Ying, complement each other, it will blend with the brand name of the pattern, forming a unique font image, a good visual effect, expressing the strong liquor brands commitment to the community, dedication to the health of consumers dedication, fully reflects the strong liquor Limited human health, never-ending "powerful" spirit of enterprise.

Packaging designers can draw ink art to express one's mind in my mind, can design their own minds realized that works. Ink art for the packaging design provides inexhaustible resources, blending the two will have a limitless future development, greater charm. Ink as a design element in the packaging design of the more common, but often seen in those with Chinese local characteristics of the product packaging, in the historic. Such as: tea, wine, pen, ink, and other local handicrafts will be mostly scattered ink abstract elements, after further graphic appears in the package, the traditional techniques and modern design combined. Packaging designers can draw ink art to express one's mind in my mind, they can design their own minds realized that the work, understanding of Chinese ink painting, inheritance and organic fusion of modern packaging design will bring new blood and breathing.

\section{Conclusions}

As one of China's traditional ink painting art essence, with distinctive ethnic characteristics, through 
the characteristics of the properties in the packaging design application will highlight the product, the packaging and to form their own style, so the use of Chinese ink art of packaging design is more ethnic and local characteristic, which is China's packaging design to the world, based on the world's fundamental. Modern packaging design trends should vary with the development of society and development, absorb and consider comprehensive factors in order to establish a sound, national, new packaging design culture body system flavor of the times, between the material and spirit of many to be the home of the whole harmony, so China modern packaging design to enhance a high degree, and then in the world, invincible. The ink art for clever graphic design, the site is one of our responsibility, but also a mission, let us work together now.

\section{References}

[1] Wang Yanyun. Minzu University of China, Vol. 6 (2007) No 53, p.25-26

[2] Yi Yongfang. Hunan Normal University, Vol. 12 (2008) No 27, p.74-76

[3] Xia Sanao. China Packaging, Vol. 1 (2008) No 19, p.144-145

[4] Yu Xueyong. Packaging Engineering, Vol. 6 (2009) No 27, p.21-23 